\title{
Abdominoperineal Resection in Rectal Cancer in General Surgery Department at Gabriel Toure University Hospital
}

\author{
Amadou Traore*, Abdoulaye Diarra, Madiassa Konate, Souleymane Thiam, Soumaila Keita, \\ Tani Kone, Boubacar Karembe, Assitan Kone, Boubacar Sidibe, Amadou Bah, Amadou Maïga, \\ Ibrahim Diakite, Bakary Tientigui Dembele, Alhassane Traore, Adegne Togo, Lassana Kante, \\ Moussa Samake, Moustapha Issa Mangane, Thierno Madane Diop, Mamadou Salia Diarra, \\ Adama Diakite, Gangaly Diallo
}

Gabriel Toure University Hospital, Bamako, Mali

Email: *amadoutra242@gmail.com

How to cite this paper: Traore, A., Diarra, A., Konate, M., Thiam, S., Keita, S., Kone, T., Karembe, B., Kone, A., Sidibe, B., Bah, A., Maïga, A., Diakite, I., Dembele, B.T., Traore, A., Togo, A., Kante, L., Samake, M., Mangane, M.I., Diop, T.M., Diarra, M.S., Diakite, A. and Diallo, G. (2019) Abdominoperineal Resection in Rectal Cancer in General Surgery Department at Gabriel Toure University Hospital. Surgical Science, 10, 16-23.

https://doi.org/10.4236/ss.2019.101003

Received: December 18, 2018

Accepted: January 13, 2019

Published: January 16, 2019

Copyright $\odot 2019$ by author(s) and Scientific Research Publishing Inc. This work is licensed under the Creative Commons Attribution International License (CC BY 4.0).

http://creativecommons.org/licenses/by/4.0/

\begin{abstract}
The objectives: Were to determine the hospital frequency of abdominoperineal resection (APR); to determine mortality and morbidity rates and to assess oncologic outcomes. Method and patients: We performed a retrospective study between 2008 and 2013 in general surgery department at Gabriel Toure University Hospital (UH) which included all patients admitted for rectal cancer confirmed by pathological examination, and having undergone an APR. Results: We have collected 17 cases which accounted for $65.38 \%$ of curative resections of rectal cancer. The sex-ratio was 0.89 and the averageage was 49.53 years. The average tumor distance from the anal verge was $4.59 \pm$ $1.7 \mathrm{~cm}$. All patients had adenocarcinoma of the rectum. The histopathologic grade was well in 7 cases, moderate and poor in 5 cases each. According to the pathologic TNM classification, 13 patients were classified T4, 14 patients $\mathrm{N}+$. APR was associated with hysterectomy and partial colpectomy in 4 cases. The average duration of interventions was $202.06 \pm 25.68$ minutes. The average duration of hospitalization was $18.24 \pm 04.89$ days. The postoperative mortality and morbidity rates were $5.88 \%$ and $29.42 \%$, respectively. Local recurrence was observed in 6 patients and liver metastasis in 2 patients. The overall survival rate was $37.5 \%$ at 2 years and $18.75 \%$ at 5 years. Conclusion: APR still occupies an important place in our practice. Our results could be improved by the recent introduction of neoadjuvant radio chemotherapy in Mali.
\end{abstract}

\section{Keywords}

Abdominoperineal, Cancer, Mali, Rectum, Resection, Surgery 


\section{Introduction}

Abdominoperineal resection (APR) of the rectum consists, by a double abdominal and perineal approach, to remove the rectum, the sphincteric apparatus, the anal canal and the mesorectumin one piece; it ends with a definitive colostomy [1].

It is indicated for cancers of the rectum for which a curative resection does not preserve the sphincter apparatus and for some anal cancers [1] [2] [3].

Colorectal cancer is the fourth most common cancer in the world [4].

In France, 42,152 new cases of colorectal cancer were estimated in 2012 $(23,226$ men and 1826 women) with 1772 deaths [5]. In the USA 143,460 new cases of colorectal cancer with 51,690 deaths were estimated in 2012 [6].

Colorectal cancer is rare in Africa. In Mali, in 2012, Coulibaly reported 81 cases of rectal cancer in 26 years in the Surgery B department of the Point G university hospital [7].

APR is a mutilating surgery that is confronted with several challenges namely: the success of an oncologic resection, the reduction of local recurrence, the preservation of urinary and sexual functions and the acceptance by the patient of a definitive colostomy.

Today, indications of APR have been reduced by the development of sphincter preserving surgeries such as low anterior resection (LRA), intersphincteric resection and coding of neoadjuvant treatments [3] [8].

The results of the APR have been improved through the introduction of total mesorectum excision (TME) and the combination of neoadjuvant chemoradiation therapy (CRT) [3] [7] [9].

In China, in 11 years, APR was performed in 172 patients at Sun Yat-sen University hospital (UH) with a mortality rate of $0 \%$ [4]. In the USA, Zaheer et al. reported 169 cases in 7 years with a mortality rate of $1.8 \%$ [10]. In the United States, Dixon et al. reported 85 cases in 10 years with a $2 \%$ mortality rate [11].

APR is poorly practiced in Africa and has received little research.

In Tunisia, Ben Temime performed 45 APR in 45 years [12]. At the UH of Treichville in Côte d'Ivoire, Casanelli reported 8 cases of APR in 28 years [13]. In Mali, the surgery B Department of the UH of Point G performed 28 APR in 26 years [7].

The objectives of this study were to determine the hospital frequency of the $\mathrm{APR}$, to determine mortality and morbidity rates and to assess oncologic outcomes.

\section{Methodology}

We performed a retrospective study in the General Surgery Department of the Gabriel Toure UH between January 1, 2008 and December 31, 2013. We Included all patients admitted for rectal cancer confirmed by pathological examination and having undergone an APR. We also confirm that we have obtained the approval of the hospital's ethics committee for the study.

The indication of the APR at the locoregional level was made prior to surgery 
after digital rectal examination and the proctoscopy which made it possible to evaluate the distance of the tumor from anal verge, and the local extension. However, the final decision was made after the intraoperative exploration.

\section{Surgical procedures}

We realized the APR according to the following principles:

- A double approach: abdominal laparotomy and perineal;

- Upper ligation of the lower mesenteric vessels;

- The rectum and the mesorectum were resected in monobloc and extra-fascial. In some patients, resection of the uterus and vagina were combinated:

- The definitive colostomy was located in left iliac fossa;

- The peritoneum was closed;

- The pelvic area was drained by two tubular drains exiting at the right and left side of perineal incision;

- The primary closure of the perineal wound was performed.

We used the UICC classification (TNM 7th edition of 2009).

The variables used were: socio-demographic data; clinical and paraclinical features about the general condition of the patient, the histological findings; therapeutics data; postoperative morbidity and mortality; the occurrence of a local recurrence and distant metastasis; survival at 2 and 5 years. These data were collected from patient records, consultation records, operating records, and records of histological findings.

The entry was made on Microsoft Office Word version 2007. The data analysis was carried out on SPSS software PASW Statistics 18. The statistical tests used were the Student $t$-test and Fisher exact test with a significance p-value less than 0.05 .

\section{Results}

We collected 17 APR cases in 6 years. These cases accounted for $23 \%$ of rectal cancer treatments (17/74), $29.82 \%$ of surgical treatments of rectal cancer (17/57) and $65.38 \%$ of curative surgical procedures (17/26) (Table 1).

The average age of the patients was 49.53 years old. The extreme ages were 24 and 80 years. The median age was 50 years. The sex-ratio was 0.89 ; there were 8 males and 9 females.

The Karnofski index was between $80 \%-100 \%$ for 15 patients and between

Table 1. Surgical treatment of rectal cancer in the department.

\begin{tabular}{ccc}
\hline Type of surgery & Effectives & Pourcentage \\
\hline APR & 17 & 29.82 \\
Anteriorresection of rectum & 9 & 15.79 \\
Lateral colostomy & 5 & 08.77 \\
Hartmann colostomy & 26 & 45.62 \\
Total & 57 & 100 \\
\hline
\end{tabular}


$50 \%-70 \%$ for 2 patients. The Body Mass Index (BMI) was normal in 13 cases and between 16.5 - 18.5 in 4 cases. The ASA classification was II and III in 11 and 6 cases, respectively. Comorbidity was found in 4 cases including 1 case of heart failure, 2 cases of acute arterial hypertension and 1 case of chronic pneumonitis.

The average distance of the tumor from the anal verge was $4.59 \pm 1.7 \mathrm{~cm}$. The extreme distances were 1 and $8 \mathrm{~cm}$.

All our patients had adenocarcinoma of the rectum. The histopathologic grade was well in 7 cases, moderate and poor in 5 cases each.

According to the pathologic TNM classification: 13 patients were classified T4, 14 patients $\mathrm{N}+, 14$ patients of stage 3 (Table 2).

The indication of APR was the invasion of the external sphincter in 7 cases, a distal resection margin less than $2 \mathrm{~cm}$ in 3 cases and a locally advanced tumor in 7 cases.

APR was combinated with hysterectomy and partial colpectomy in 4 cases.

The average duration of interventions was $202.06 \pm 25.68$ minutes. The minimum and maximum durations were 150 and 240 minutes.

The average duration of hospitalization was $18.24 \pm 04.89$ days with extremes of 11 and 28 days.

The morbidity at 30 days of surgery was $29.41 \%$ and mortality was $5.88 \%$ (Table 3 ). The 4 cases of infections were managed by drainage after suture ablations followed by dry dressing changes. The case of urinary retention required to keep the bladder catheter several days. At six months outcomes were simple in 13 patients (76.47\%) (Table 4); sexual and urinary dysfunction were the main complications (3 cases).

Table 2. Distribution of patients according to TNM classification.

\begin{tabular}{cccc}
\hline & & Effectives & Percentage \\
\hline T & T2 & 1 & 05.9 \\
& T3 & 3 & 17.6 \\
& Total & 13 & 76.5 \\
& N0 & 17 & 100.0 \\
N & N1 & 3 & 17.7 \\
& N2 & 10 & 58.8 \\
& Total & 4 & 23.5 \\
M & M0 & 17 & 100 \\
& M1 & 17 & 100 \\
& Total & 00 & 00 \\
& Stage 2 & 17 & 100 \\
& Stage 3 & 3 & 17.6 \\
& Total & 14 & 82.4 \\
& & 17 & 100
\end{tabular}


Table 3. Distribution of patients according to postoperative complications at 30 days.

\begin{tabular}{ccc}
\hline & Effectives & Pourcentage \\
\hline Simple outcomes & 11 & 64.70 \\
laparotomy wound infection & 2 & 11.77 \\
Perineal wound infection & 2 & 11.77 \\
Urinary retention & 1 & 05.88 \\
Deceased & 1 & 05.88 \\
\hline
\end{tabular}

Table 4. Distribution of patients according to operative follow-up at 6 months.

\begin{tabular}{ccc}
\hline & Effectives & Pourcentage \\
\hline Simple outcomes & 13 & 76.47 \\
Sexual impotence & 2 & 11.77 \\
Urinary incontinence & 1 & 11.77 \\
Stomy prolapse & 1 & 05.88 \\
Eventration & 1 & 05.88 \\
Deceased & 2 & 11.77 \\
\hline
\end{tabular}

Adjuvant chemotherapy was performed in 11 patients (64.7\%). Radiation therapy has not been performed.

Overall survival rate at 01 year was $75 \%$. At 02 years, overall survival rate was estimated at $37.5 \%(n=6 / 16) .01$ patient was lost to follow-up. The overall survival rate at 05 years was $18.75 \%(n=03 / 16) .6$ patients had local recurrence (37.5\%) and 2 patients had liver metastasis.

\section{Discussion}

The limit of our study is essentially the lack of information on certain data due to the retrospective nature of the study and the context of resource-limited country indeed; we have excluded discussing variables such as quality of resection, nervous and vascular involvement in histological results.

APR is a mutilating surgery that has seen its frequency decrease in recent years in favor of sphincteric preservation techniques. In European, American and Asian studies, APR is less frequently performed than sphincteric preservation techniques (anterior resection and intersphincteric resection) with a frequency that varies between 16 and 41\% [4] [14] [15] [16] [17]. On the other hand, APR is more frequent in our study as in the Ivorian study $(61.54 \%$ and 65.38\%) [13]. This could be the consequence of the late diagnosis of cancer in Mali and in sub-Saharan Africa [13], and also the non-achievement, in our study, of neoadjuvant radiochemotherapy normally indicated for locally advanced rectal cancers (T3, T4 and/or $\mathrm{N}+$ ) [8]. This neoadjuvant treatment conserves the anal sphincter in some patients by inducing downstaging [18] [19].

The sex ratio varies between 1.3 and 2.02 in the literature with male predo- 
minance [4] [10] [12] [15] [20]. However, in our series, females were more common with a sex ratio of 0.89 . This could be due to a sampling bias.

The average age in our study ( 49.53 years) is close to that reported by Casanelli in an Ivorian study (42.3 years) [13]. Our patients were significantly younger than those in the European, American and Asian series (55 to 67 years) [4] [10] [15] [20] [21].

The stage of evolution of rectal cancer is an independent variable that has an impact on the results of curative treatment. Indeed, advanced stage is a factor of poor prognosis for local recurrence and survival [4] [15] [22]. In our study, 14 out of 17 patients $(82.4 \%)$ had TNM III stage cancer. This rate is significantly higher than those observed in western series (10\% to 39\%) [22] [23]. This could be explained by the delay of consultation in our series.

The morbidity of APR in our study (29.4\%) is comparable to that of the literature $(16.6 \%$ to $41 \%)$ [12] [21] [24] [25]. This was in our study, in 4 out of 6 cases, infectious complications.

The mortality associated with this surgical technique varies in the literature between $0 \%$ and $5.5 \%$ [4] [10] [11] [12] [20] [21] [24]. In our study it was 5.88\%.

The local recurrence rate is significantly higher in our study than in most other studies (37.5\% vs $8 \%$ to14.7\%) [4] [11] [20] [22]. This difference could be explained by the advanced stage of cancer and the non-realization of neoadjuvant chemoradiotherapy in our study. Indeed, Bonadeo in Argentina [16] and Fick in the Netherlands [26] who did not perform neoadjuvant chemoradiotherapy in their studies, find results statistically identical to ours $(27.6 \%$ and $15 \%, p=0.07$ and 0.26 ). The occurrence of local recurrence after resection of a cancer of the lower or middle rectum depends on the local stage of the tumor, the realization of a neoadjuvant radiochemotherapy for tumors in stages II and III, the quality of the resection of the mesorectum [1] [8] [22].

The overall 5-year survival rate for rectal cancer after APR ranges from 55 to $80 \%$ [4] [8] [10] [20]. It was low in our study (18.75\%). The variables influencing survival after APR for rectal cancer are: invasion of the resection margin, $\mathrm{T}$ and TNM stages, histological grade and radiochemotherapy [4] [8] [10]. Most of our patients had advanced cancer and no patients received neoadjuvant radiotherapy.

\section{Conclusion}

APR remains the standard treatment for locally advanced low rectal cancers. It still occupies an important place in our practice. The morbidity and mortality rates in our study are not significantly different from those in the literature. However, we had a high local recurrence rate and a low survival rate. APR must be integrated into a multidisciplinary management of rectal cancer planned during multidisciplinary consultations to improve the local control and to obtain a better prognosis.

\section{Conflicts of Interest}

The authors declare no conflicts of interest regarding the publication of this paper. 


\section{References}

[1] de Calan, L., Gayet, B., Bourlier, P. and Perniceni, T. (2004) Chirurgie du cancer du rectum par laparotomie et par laparoscopie [Open and Laparoscopic Rectal Resection for Rectal Cancer]. Encyclopédie Médico-Chirurgicale, 1, 231-274.

[2] Fourtanier, G. and Gravie, J.F. (1992) Amputation Abdominopérinéale. Encyclopédie Médico-Chirurgicale, $15 \mathrm{p}$.

[3] Mauvais, F., Sabbagh, C., Brehant, O., Viart, L., Benhaim, T., Fuks, D., Sinna, R. and Regimbeau, J.-M. (2011) The Current Abdominoperineal Resection: Oncological Problems and Surgical Modifications for Low Rectal Cancer. Journal of Visceral Surgery, 148, e85-e93. https://doi.org/10.1016/j.jviscsurg.2011.03.001

[4] Chen, Z.H., Song, X.M., Chen, S.C., Li, M.Z., et al. (2012) Risk Factors for Adverse Outcome in Low Rectal Cancer. World Journal of Gastroenterology, 18, 64-69. https://doi.org/10.3748/wjg.v18.i1.64

[5] Binder-Foucard, F., Bossard, N., Delafosse, P., Belot, A., Woronoff, A.S. and Remontet, L. (2014) Cancer Incidence and Mortality in France over the 1980-2012 Period: Solid Tumors. Revue d Epidémiologie et de Santé Publique, 62, 95-108. https://doi.org/10.1016/j.respe.2013.11.073

[6] Siegel, K., Naishadham, D. and Jemal, A. (2012) Cancer Statistics, 2012. CA: $A$ Cancer Journal for Clinicians, 62, 10-29. https://doi.org/10.3322/caac.20138

[7] Coulibaly, B., Traoré, D., Togola, B., Dembélé, M., Traoré, I., Ongoïba, N., et al. (2012) Cancer du rectum: Aspects Epidémio-Clinique, traitement chirurgical et pronostic. Mali Médical, 27, 7-10.

[8] Laurent, C. and Rullier, E. (2007) Traitement des cancers du bas rectum. Hépato-Gastro, 14, 45-53.

[9] Ferenschild, F.T.J., Dawson, I., De Wilt, J.H.W., De Graaf, E.J.R., Groenendijk, R.P.R. and Tetteroo, G.W.M. (2009) Total Mesorectal Excision for Rectal Cancer in an Unselected Population: Quality Assessment in a low Volume Center. International Journal of Colorectal Disease, 24, 923-929.

https://doi.org/10.1007/s00384-009-0732-0

[10] Zaheer, S., Pemberton, J.H., Farouk, R., Dozois, R.R., Wolff, B.G. and Llstrup, D. (1998) Surgical Treatment of Adenocarcinoma of the Rectum. Annals of Surgery, 227, 800-811. https://doi.org/10.1097/00000658-199806000-00003

[11] Dixon, A.R., Maxwell, W.A. and Holmes, J.T. (1991) Carcinoma of the Rectum: A 10 Years' Experience. British Journal of Surgery, 78, 308-311. https://doi.org/10.1002/bjs.1800780314

[12] Ben Temime, L., Trabelsi, O., Ben Moussa, M., Haouet, K., Kacem, C., El Hachaichi, A., Abdesselem, M.M. and Zaouche, A. (1997) Les amputations abdominopérinéales pour adénocarcinome du rectum. Technique et résultats. A propos de 45 cas. Tunisie Médicale, 75, 912-918.

[13] Casanelli, J.M., Blegole, C., Moussa, B., N’Dri, J., Aboua, G., Yamossou, F., Sidibe, A., Keli, E. and N'Guessan, H.A. (2005) Cancer du rectum. Aspects épidémiologiques, cliniques et thérapeutiques à propos de 16 cas au CHU de Treichville. Mali Médical, 20, 21-23.

[14] Marr, R., Birbeck, K., Garvican, J., Macklin, C.P., Nicholas, J. and Parsons, W.J. (2005) The Modern Abdominoperineal Excision the Next Challenge after Total Mesorectal Excision. Annals of Surgery, 242, 74-82. https://doi.org/10.1097/01.sla.0000167926.60908.15

[15] Omidvari, S., Hamedi, S.H., Mohammadianpanah, M., Razzaghi, S., Mosalaei, A., 
Ahmadloo, N., et al. (2013) Comparison of APR and Low Anterior Resection in Lower and Middle Rectal Cancer. Journal of the Egyptian National Cancer Institute, 25, 151-160. https://doi.org/10.1016/j.jnci.2013.06.001

[16] Bonadeo, F.A., Vaccaco, C.A., Benati, M.L., Ojea Quintana, G.M., Garione, X.E. and Talenta, M.D. (2001) Rectal Cancer: Local Recurrence after Surgery without Radiotherapy. Diseases of the Colon \& Rectum, 44, 374-379. https://doi.org/10.1007/BF02234736

[17] Tilney, H.S., Heriot, A.G., Purkayastha, S., Antoniou, A., Aylin, P., Darzi, A.W. and Tekkis, P.P. (2008) A National Perspective on the Decline of Abdominoperineal Resection for Rectal Cancer. Annals of Surgery, 247, 77-84. https://doi.org/10.1097/SLA.0b013e31816076c3

[18] Kim, N.K., Baik, S.H., Seong, J.S., Kim, H., Roh, J.K., Lee, K.Y., Sohn, S.K. and Cho, C.H. (2006) Oncologic Outcomes after Neoadjuvant Chemoradiation Followed by Curative Resection with Tumor-Specific Mesorectal Excision for Fixed Locally Advanced Rectal Cancer. Impact of Postirradiated Pathologic Downstaging on Local Recurrence and Survival. Annals of Surgery, 244, 1024-1030. https://doi.org/10.1097/01.sla.0000225360.99257.73

[19] Rullier, E., Goffre, B., Bonnel, C., Zerbib, F., Caudry, M. and Saric, J. (2001) Preoperative Radiochemotherapy and Sphincter-Saving Resection for T3 Carcinomas of the Lower Third of the Rectum. Annals of Surgery, 234, 633-640.

https://doi.org/10.1097/00000658-200111000-00008

[20] Luna-Pérez, P., Rodríguez-Ramírez, S., Vega, J., Sandoval, E. and Labastida, S. (2001) Morbidity and Mortality Following Abdominoperineal Resection for Low Rectal Adenocarcinoma. Revista de Investigacion Clinica, 53, 388-395.

[21] Kirzin, S., Portier, G., Nouaille de Gorce, H., Guimbaud, R. and Lazorthes, F. (2009) Morbidité des amputations abdominopérinéales: Bénéfices de la colostomie périnéale. Gastroentérologie Clinique et Biologie, 33, 137. https://doi.org/10.1016/S0399-8320(09)72869-6

[22] Silberfein, E.J., Kattepogu, K.M., Hu, C.Y., Skibber, J.M., Rodriguez-Bigus, M.A., Feig, B., et al. (2010) Long-Term Survival and Recurrence Outcomes Following Surgery for Distal Rectal Cancer. Annals of Surgical Oncology, 17, 2863-2869. https://doi.org/10.1245/s10434-010-1119-8

[23] De Campos-Labato, L.F., Alves-Ferreira, P.C., Lavery, I.C. and Kiran, R.P. (2011) Abdominoperineal Resection Does Not Decrease Quality of Life in Patients with Low Rectal Cancer. Clinics, 66, 1035-1040. https://doi.org/10.1590/S1807-59322011000600019

[24] Ele, N., Okiemy, G., Koutaba, E., Chocolat, R., Massamba, M.D., Ibamba, A., Datse, Y. and Massengo, R. (2003) L'amputation abdominopérinéale du rectum au CHU de Brazzaville: Résultats d'une série de 18 cas. Journal Africain de Chirurgie Digestive, 3, 288-291.

[25] Grumann, M.M., Noak, E.M., Hoffmann, I.A. and Schlag, P.M. (2001) Comparison of Quality of Life in Patients Undergoing Abdominoperineal Extirpation or Anterior Resection for Rectal Cancer. Annals of Surgery, 233, 149-156. https://doi.org/10.1097/00000658-200102000-00001

[26] Fick, T.E., Baeten, C.G., Von Meyenfeldt, M.F. and Orbertop, H. (1990) Recurrence and Survival after Abdominoperineal and Low Anterior Resection for Rectal Cancer, without Adjunctive Therapy. European Journal of Surgical Oncology, 16, 105-108 